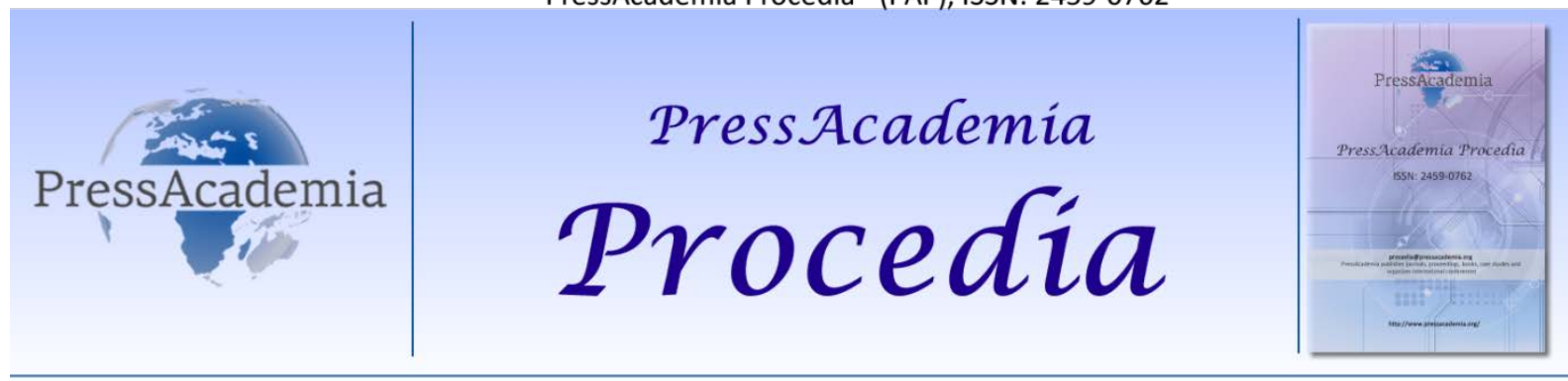

Global Business Research Congress (GBRC), May 26-27, 2016, Istanbul, Turkey.

\title{
ACCEPTANCE OF MANAGEMENT INFORMATION SYSTEMS IN ENTERPRISES
}

\section{DOI: 10.17261/Pressacademia.2016118685}

\author{
Naciye Guliz Ugur ${ }^{1}$, Tugba Koc ${ }^{2}$ \\ ${ }^{1}$ Sakarya University, ngugur@sakarya.edu.tr \\ ${ }^{2}$ Sakarya University, tcekici@sakarya.edu.tr
}

\begin{abstract}
The adoption and use of management information systems by enterprises is a complicated process. Despite the known advantages of MIS implementation in enterprises, there are very few enterprises in Turkey that incorporate intra-organizational information systems. This study is aimed at identifying the problems and challenges of adopting MIS and provides a conceptual framework for considering the problems. A single-case research is adopted with both qualitative and quantitative approach. Three important cluster of IS success factors are identified as motivation, investment and scope of use. A model is proposed for the empirical study and the employees of the enterprise have been participated in the emailed instrument survey. The findings indicate that social influence and attitude towards technology use are two significant factors on intention to use information systems in enterprises. The present study reveals the different factors that influences the adoption of management information systems based on organizational culture and readiness. Strong motivation is one of the critical success factors in adoption of management information systems in enterprises. Moreover, the scope of use and the design of the developed system have significant impact in its successful adoption and continuous usage. Implications and suggestions for future research are provided.
\end{abstract}

Keywords: Management Information Systems, UTAUT, organizational readiness, empirical research, qualitative research JEL Codes: D20, C25, D22

\section{INTRODUCTION}

The adoption and use of MIS by enterprises as proved is a complicated process. However, Turkey as a developing country is moving forward slowly in adopting management information systems in enterprises. Unified Theory of Acceptance and Use of Technology (UTAUT) is used to explain user intentions to use an IS and subsequent usage behavior.

The culture of enterprises are discussed in the literature as one of the factors that has significant impact in IS success in different countries. The research of Geert Hofstede (1983) has shown that cultural differences between nations are especially found on the deepest level; i.e. on the level of values. In comparison, cultural differences among enterprises are especially identified on the level of practices. The Organizational Cultural model developed by Bob Waisfisz (1992) consists of six autonomous dimensions and two semi-autonomous dimensions: Means oriented/ goal oriented, internally driven/externally driven, easy going work discipline/strict work discipline, local/professional, open system/closed system, employee oriented/work oriented, the degree of acceptance of leadership style and the degree of identification.

This study also reviews organizational readiness. As an enterprise-level construct, readiness for change refers to organizational members' shared resolve to implement a change (change commitment) and shared belief in their collective capability to do so (change efficacy). Organizational readiness for change varies as a function of 
how much organizational member's value the change and how favorably they appraise three key determinants of implementation capability: task demands, resource availability, and situational factors. When organizational readiness for change is high, organizational members are more likely to initiate change, exert greater effort, exhibit greater persistence, and display more cooperative behavior (Weiner, 2009).

\section{RESEARCH FRAMEWORK}

This study proposes hypotheses on the influences of organizational culture of innovation and organizational readiness to change on the four factors of technology acceptance model. In addition it tests the relationships between four key factors of acceptance and intention to use of the information systems in the enterprise (Figure 1).

Figure1: Research model

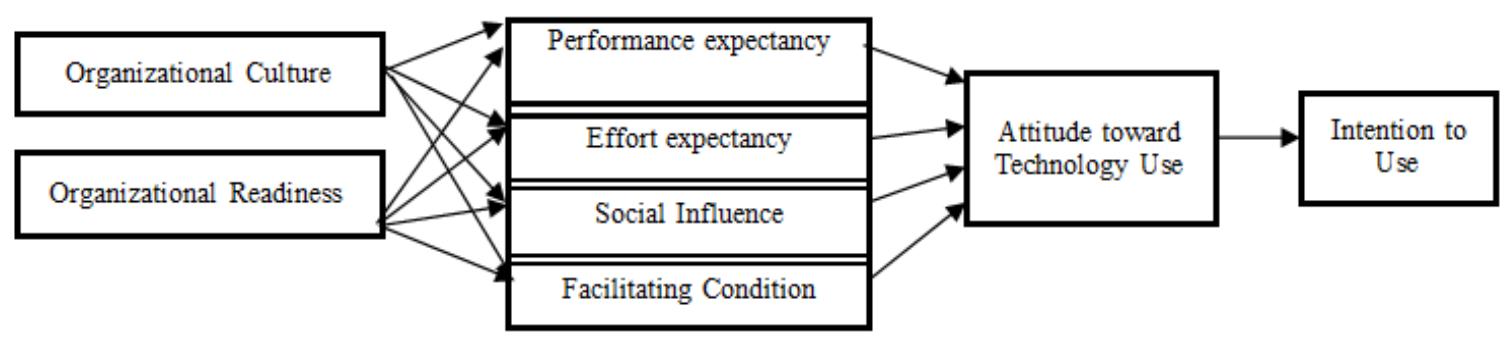

H1: Higher level of innovative culture in enterprise will lead to higher level of technology acceptance factors.

H2: Higher level of organizational readiness to change will lead to higher level of technology acceptance factors.

H3: Higher level of performance expectancy leads to higher level of intention to use information systems.

H4: Higher level of effort expectancy leads to higher level of intention to use information systems.

H5: Higher level of social influence leads to higher level of intention to use information systems.

H6: The better the facilitating condition leads to higher level of intention to use information systems.

H7: The better the attitude towards technology use leads to higher level of intention to use information systems.

\section{DATA AND METHODOLOGY}

In order to fulfill the purpose of this study, both qualitative and quantitative methods applied. The qualitative study includes interview of managers at top management level of the enterprise through phone calls. Three managers from the senior management team have been interviewed: head of ICT, head of central project control and head of finance department. All interviews were audio recorded. The transcripts were prepared and compared to extract the common themes. The study followed by survey instrument that have been mailed to the employees. The instrument was developed in English language and translated to Turkish language. A bilingual expert was assigned to conduct a back-translation to English to address the potential conceptual or cultural discrepancies. The instrument has been pre-tested with three individuals as the representatives of the target population. Multiple regression method is applied to test the proposed empirical model.

\section{QUALITATIVE RESEARCH AND FINDINGS}

This article applied a single-case study approach of an engineering company in Turkey. This company is a general contractor in metallurgy, oil and gas, and mine projects in Turkey which has been in operation for about 40 years. It provides full engineering, procurement, and construction (EPC) services for large scale industrial projects. It is one of the pioneers in adopting MIS in Turkey. This company is a technical holding enterprise with twelve subsidiaries and affiliates. One of the affiliates is focused on MIS and automation 
services for industry. The current system incorporates all data and information about projects, engineering, IT and ICT, procurement, human resource, finance, management, administration and services. The system enables the enterprise to share information and to electronically conduct business across enterprise's three branches in two different cities. Therefore the management is very critical and the management information system has to incorporate features of inter- organizational information systems to harmonize the relationships between different branches. The access to each level of information is provided based on the enterprise chart. The successful implementation of the system depended on a set of critical successful factors. The most important and distinctive success factor in this case is listed in three clusters: motivation, scope of use and investment.

\subsection{Decision Motivation}

When corporations were considering MIS, the factors that motivated them to adopt the system were extremely significant for their future success. Therefore strong motivation became one important factor to influence the success of the system. "With regards to the nature of work of the company which involves in various projects, MIS provides the facility to store information based on the projects separately. For instance, the information regarding revenues, costs, purchase orders, contracts, activities, project progress and consumption of each project is collected through the system and is available to the users at any point of time. Moreover the comparison between different projects in terms of financial information is improved and facilitated. In this enterprise, strong ties and harmony required to be established among different departments."

\subsection{Scope Of Use}

This cluster focuses on usage of the system. The success factor is discussed with more attention to detailed operational and management aspects in application of the system. The scope of use of the system is very wide and the system is designed and implemented in a way that certain tasks cannot be done without using the system. "The only way to write, number and sign a letter is through the system. The number of all letters is provided by the system and all letters are digitally signed by the top management through the system. A copy of all letters will be saved in the archive. It makes all letters available and searchable. This is an important issue for the management because of the variety of the nature of the work in this company. This process improves the productivity specially when there are letters that need to be sent to branches in other cities."

\subsection{Investment}

There is a long tradition in business that capital expenditure must be formally justified in terms of the benefits to the enterprise. Therefore, when a new technology is required to be purchased, a capital investment appraisal needs to be undertaken (Remenyi et al.,1995). The justification for investing in a new information system would therefore include not only cost issues but also functionality, alignment with business processes, opinion of users and compatibility with current technology. Recognition of the potential impact of IT systems on the strategic position of companies, as well as increasing levels of IT spent, have made the control and justification of IT investment a critically important issue. In Turkey the need for investment in management information systems has not been recognized and justified yet in many enterprises. "It is difficult to justify the investment for management information systems in many enterprises. 10 years ago the company decided to expand its services from metallurgy to broader aspect of oil and gas industry. Therefore to handle larger projects, the company had to strengthen its management skills. It was always an important issue to have a strong management team with engineering skills. In Turkey there are very few companies who provide EPC services and they usually fail because of deficiencies in management. Therefore it has been always crucial to have a strong management system and invest on it for improvements."

\subsection{Enterprise Culture And Readiness}

Despite the extensive literature with regard to the culture of innovation and discussions on impacts of enterprise's culture of innovation facilitates technology adoption, in this case innovation is not playing an important role in adoption of management information system. All three interviewees believed that the 
company is not innovative and is not open to new and creative ideas. However they believed that the company is more goal oriented with strict work discipline. The interviewees agreed that the company is more focused on professional work ethics and more work oriented rather than employee oriented. The support from the top management team is not recognized as a significant factor in success of the implementation of the management system and due to several changes in management team in recent years the influence of management in implementation and usage of the system is questionable. The interviewees believe that the culture of usage of the system is independent from managerial support and influence.

\subsection{Empirical Results}

Data for the study were collected through an emailed survey instrument to the enterprise for this case research in Turkey. The survey instrument were adopted mostly from Venkatesh et al. (2003) instrument and slightly modified for some words to match the concept of this study. Total number of respondents is $53.83 \%$ of the respondents were male while $17 \%$ were female. $32 \%$ of respondents were between 25 to 35 years old and $32 \%$ were between 36 to 45 years old while $35 \%$ were above $45.30 \%$ of the respondents were not among the management team however $24 \%$ were among the lower management and $23 \%$ were among the higher management team. This study was fortunate to include $23 \%$ of the respondents from the senior management group. $26 \%$ of the respondents had less than five years of work experience while $30 \%$ had five to ten years of work experience and $53 \%$ had more than ten years of experience. $62 \%$ of the respondents claim that they use the system every day. Effort expectancy and performance expectancy are presenting higher values compare to intention to use.

The empirical results on organizational culture are aligned to the finding of the interviews. The enterprise is not identified as highly innovative in general. About $38 \%$ of the respondents believed that the enterprise has no consistent strategic approach while only $6 \%$ believed that the enterprise is highly innovative. The enterprise is not identified as a risk taking company and resistance to change is dominant in both employees and management. The results of the survey instrument verify this matter. The majority of respondents believe that the speed of change is very slow in the enterprise with low level of complexity and newness. They believe the changes are very predictable in the enterprise.

Two models are identified with significant explained variance. Model 1 included the attitude towards technology use influence on intention to use. Model 2 included the attitude towards technology use and social influence impact on intention to use. The results reveal that other defined independent variables (effort expectancy, performance expectancy and facilitating conditions) were not significantly influence the dependent variable (intention to use). Also the influence of organizational culture of innovation and readiness to change were not supported by the data in this case research. The explained variance of model 1 was significant; R2 was 0.7. The explained variance for model 2 were also significant with higher R2 of 0.82 ( $F$ change $=10.475, p<0.1$ ). The regression analysis summary results are shown in table 1 . For the proposed hypotheses, this study found support for hypotheses 5 and 7. Higher level of social influence have significant positive influence on intention to use and better attitude towards technology usage have positive impact on intention to use information systems in this case research.

Table 1: Model Summary

\begin{tabular}{|l|l|l|c|c|c|}
\hline \multicolumn{1}{|c|}{ Model } & \multicolumn{1}{|c|}{$\mathbf{R}$} & \multicolumn{1}{|c|}{ R Square } & $\begin{array}{c}\text { Adjusted R } \\
\text { Square }\end{array}$ & $\begin{array}{c}\text { Std. Error of the } \\
\text { Estimate }\end{array}$ & p-value \\
\hline Model 1 & $0.838^{\mathrm{a}}$ & 0.70 & 0.70 & 1.94 & 0.000 \\
\hline Model 2 & $0.903^{\mathrm{b}}$ & 0.82 & 0.81 & 1.54 & 0.000 \\
\hline
\end{tabular}

a. Predictors: (Constant), AT; b. Predictors: (Constant), AT, SI;

\subsection{DISCUSSION}

The present study reveals the different factors that influences the adoption of management information systems based on organizational culture and readiness. Specifically three clusters are identified as decision 
motivation, scope of use and investment. Strong motivation is one of the critical success factors in adoption of management information systems in enterprises. Specifically in Turkey as a developing country the acceptance of new technologies is on the rise and several enterprises are moving forward to incorporate these technologies in management systems and improve their operational efficacy, effectiveness and competitiveness. The justification for investing in a new information system would therefore include not only cost issues but also functionality, alignment with business processes, opinion of users and compatibility with current technology. Recognition of the potential impact of IT systems on the strategic position of companies, as well as increasing levels of IT spent, have made the control and justification of IT investment a critically important issue. Moreover, the scope of use and the design of the developed system have significant impact in its successful adoption and continuous usage. Furthermore, contrary to the expectations, the present study found that organizational culture of innovation and organizational readiness to change does not have significant impact on technology acceptance factors and intention to use information systems. However attitude towards technology usage and social influence are identified as factors that have positive significant impact on intention to use information systems in enterprise.

The adoption of organizational information systems generally requires significant commitments of both financial and operational resources. These commitments are indication of the firm's reliance and belief in the ability of information systems to aid in achieving the firm's strategic goals. Thus, not all firms are convinced to adopt these systems. Some firms adopt the information systems due to their trading partners or market conditions, however sometimes the results from implementing the system do not make significant strategic contributions to the firm's accomplishments. This is important implication of this research for managers in enterprises to identify the strategic benefits of implementing management information system in their enterprises and identify the motivations and allocate investments. In addition, the attitude toward technology use is an important factor that affects the intention to use new technologies and specifically information systems. This is an aspect of research which has not gained great deal of attention in the literature. Researchers may identify the techniques to improve attitude and more studies need to be done in comprehending the social influences of IS adoption.

\section{CONCLUSION}

This study is based on IS success and technology acceptance and adoption theories applied to MIS success. In short, it was clear that the significant factors in management information adoption are motivation, investment and scope of use. In addition social influence and attitude towards technology use are identifies as significant factors in intention to use information systems in enterprises. However, organizational culture of innovation and organizational readiness to change are not identified as significant indicators of IS adoption the in the Turkish context.

\section{REFERENCES}

Hofstede, Geert. "The cultural relativity of organizational practices and theories." Journal of international business studies (1983): 75-89.

Waisfisz, Bob (1992), Intercultural Cooperation between Germans and Sri Lankans, Gesellschaft für technische Zusammenarbeit (GTZ)/Institute for Training in Intercultural Management (ITIM), unpublished paper

Weiner, Bryan J. "A theory of organizational readiness for change." Implement Sci 4.1 (2009): 67.

Remenyi, Dan, and Brian Williams. "Some aspects of methodology for research in information systems." Journal of Information Technology 10.3 (1995): 191-201.

Venkatesh, Viswanath, et al. "User acceptance of information technology: Toward a unified view." MIS quarterly (2003): $425-478$. 